\title{
Community versus Institutional Meanings of Child Poverty: Implications for Policy for Reducing Child Poverty
}

\author{
Dr. Grace Alenoma \\ Department of Social, Political, and Historical Studies, University for Development Studies, Wa Campus, \\ Ghana. \\ E-mail: $\underline{\text { alenoma72@yahoo.co.uk }}$
}

\begin{abstract}
Knowledge on different meanings of child poverty is important for reducing child poverty because it is critical for designing effective policies and programs aimed at addressing issues surrounding children's well-being. Reducing child poverty is important for overall poverty reduction and inequality because increase and perpetuation of child poverty can result in intergenerational transmission of poverty. However, the relatively young status of the concept of child poverty, make its meaning(s) unclear. Although some efforts have been made by researchers and development agencies towards an understanding of the concept of child poverty, its meaning and indicators are scattered in the literature and remain unclear. Due to children's dependence on adults for their wellbeing, policy frameworks aimed at reducing child poverty need to take into account both community and institutional meanings of child poverty because adults' understanding of child poverty at the community level have consequences for how they treat and deal with issues relating to children well-being/illbeing. This paper re/presents some meanings of child poverty at the institutional and community levels using secondary materials drawn from both developing and developed country context and primary materials from four rural communities in Northern Ghana. The policy implications and policy options for reducing child poverty base on meanings of child poverty are indicated.
\end{abstract}

Keywords: Child poverty, meanings of child poverty, reducing child poverty

DOI: $10.7176 /$ RHSS/9-2-16

\section{Introduction}

Due to the relatively young status of the concept of child poverty, its meaning is unclear as attempts to contribute to understanding its meaning and indicators are scattered in the literature of child poverty. Yet, knowledge of meanings of child poverty are important for policy/policies which aim (s) at reducing child poverty. Efforts at reducing poverty in general need to prioritize child poverty and knowledge on the meanings and indicators of child poverty are important.

Literature on child poverty both from a conceptual point of view and empirical evidence suggests it is a social construct and it has varied meanings. Despite its social constructivist nature, empirical evidence indicates in reality children experience it and have their own construct of child poverty. Several literatures; (Abebe, 2014; Young Lives, 2012; UNICEF, 2011; Camfield, 2010; Muninjin et al, 2006; Thomas, 2005 and Witter and Bukokhe, 2004) indicate child poverty is multi-dimensional and different from poverty associated with adults. The effects of poverty on children are damaging and permanent compared to adults (UNICEF, 2011).

According to UNICEF, in 2013, 385 million children representing 83 percent of children in the developing world were extremely poor. Reducing the number of children living in poverty will require policy/policies and programs which take into account meanings of child poverty at both the institutional and community levels because meanings of child poverty are critical for the design of any policy or program which can work to take children out of poverty. Child poverty is experienced by children and therefore the meaning ( $\mathrm{s}$ ) they give to child poverty could be a reflection of their experience of it. Although child poverty is associated with children, at the community/household level adults play a major role in determining the poverty status of children because of children's dependence on adults.

Definitions of child poverty based on child survival and material indicators of child development are popular among development agencies (Jones and Sumner, 2011). While these ways of looking at child poverty are useful they are likely to overlook other areas of well-being and the particular situation of children in specific societies (Jones and Sumner, 2011). Yet, international agencies such as UNICEF have been at the center stage of efforts at enhancing children wellbeing through policies and programs. 
Until recently, discussions about poverty at both national and international levels either in terms of definitions/measurements or its reduction strategy/strategies did not make distinctions between poverty as it applies to children and also adults. Child poverty as a standalone concept is less than 2 decades old with the very first scientific measurement of it in developing countries carried out by Gordon et al (2003) and sponsored by UNICEF.

Aside UNICEF's interest in issues surrounding child poverty including unearthing its meanings and indicators, some childhood researchers interested in child wellbeing have carried out studies in both developed and developing countries context. Child poverty, it is argued, is different from poverty associated with adults because there are differences in the needs of adults and also among children depending on their ages (Jones and Sumner, 2011). National policies and programs of most countries in the world aimed at addressing issues relating to child poverty are often inspired by meanings and indicators of child poverty emanating from international organizations such as UNICEF. For instance, the UN Sustainable Development Goal 1 - end extreme poverty in all its form everywhere and which comes with its associated component parts and indicators slated to be achieved by 2030, mandates all member countries especially those in the developing world to chart their development agenda in a manner which will lead to the realization of this goal. Although this constitutes a good move to addressing extreme poverty for example, it is doubtful if community meanings of extreme poverty are consistent with the meanings and indicators this goal seeks to address.

Therefore, this paper seeks to re/present some meanings of child poverty from available literature as well as meanings of child poverty generated from primary materials from some rural communities in the Upper West and Northern regions of Ghana and to highlight the policy implications for reducing child poverty. The paper does not aim at reproducing all existing meanings of child poverty. Rather it aims at highlighting difference(s) and similarities in meanings of child poverty at the institutional and community levels and to indicate policy strategies which could work for reducing child poverty.

Following this introduction, the paper begins with some meanings of child poverty at the institutional level. Then some meanings/understandings of child poverty at the community level from both children and adults' viewpoints are presented from both developing and developed country context.

\section{Some meanings and indicators of child poverty at the institutional level}

In this section on meanings and indicators of child poverty from institutional perspective literature was taken from secondary materials from UNICEF and some child poverty literature from other researchers in both developed and developing countries.

In The State of the World's children 2005: Childhood under Threat, UNICEF (2005a) provided a definition of child poverty or children who are said to be living in poverty. "Children living in poverty experience deprivation of the material, spiritual and emotional resources needed to survive, develop and thrive, leaving them unable to enjoy their rights, achieve their full potential or participate as full and equal members of society" (UNICEF, 2005a, p. 20). This view of child poverty invariably is linked to the United Nations declaration on the rights of the child in that the definition suggests when children are unable to enjoy their rights it means they are living in poverty. Children who enjoy their rights enshrined in the UN Convention on the Rights of the Child ultimately will survive and thrive and also are more likely not to experience material and emotional deprivation.

In an earlier study of child poverty limited only to developing countries by Gordon et al (2003) child poverty was also defined from material and deprivation perspective. Child poverty is associated with children who are deprived some identifiable needs considered basic to survival and the well-being of children. These included food, safe drinking water, sanitation facilities, health, shelter, education, information and basic social services. These deprivation indicators were further classified into mild, moderate, severe and extreme depending on the level of deprivation. A child who is deprived any two of these indicators is considered to be extremely poor. It could be observed that aside education especially at the basic level which is related directly to only children's needs because ideally primary and secondary education are attended by children, all the other dimensions of child poverty outlined by Gordon et al (2003) are not exclusively to children but also adults. It could be argued that this view of child poverty emanate from adults' perspectives because the researchers used Demographic Sample Survey, Living Standards Surveys and Multi Indicator Cluster Surveys data sets as well as reports which are usually generated without the viewpoints of children.

In a study which involved 29 industrialized countries in the world and which used the 2009 round of the European Union Statistics on Income and Living Conditions (EU-SILC) data, 14 child poverty indicators were 
constructed by UNICEF (2012). The notion of child poverty was extended beyond the deprivation angle to include a relative definition. In this context a child qualifies to be labelled poor if he/she lacks two or more of the following indicators of child poverty the study listed.

Three meals a day

At least one meal a day with meat, chicken, or fish (or vegetarian equivalent)

Fresh fruit and vegetables everyday

Books suitable for the child's age and knowledge level (not including schoolbooks)

Outdoor leisure equipment (bicycle, roller-skates etc.)

Regular leisure activities (swimming, playing an instrument, participating in youth organizations etc.

Indoor games (at least one per child, including educational baby toys, building blocks, board games, computer games etc.)

Money to participate in school trips and events

A quiet place with enough room and light to do homework

An Internet connection

Some new clothes (i.e. not all second hand)

Two pairs of properly fitting shoes (including at least one pair of all-weather shoes)

The opportunity, from time to time, to invite friends home to play and eat

The opportunity to celebrate occasions such as birthdays, name days, religious events, etc.

(UNICEF, 2012 p 2 and 6)

Again, this institutional standpoint of child poverty is about what adults think child poverty means and what its indicators should be because the source of data from which the meaning and indicators emanate are primary materials generated from adults.

Abebe (2014) and UNICEF (2011) list child mortality, nutritional status of children and the incidence of maternal mortality as indicators of child poverty. Abebe further emphasizes analysis of the impacts of social change on the lives of children and the importance of children's health in the conceptualization of child poverty. Maternal mortality stated as an indicator of child poverty is an interesting point in attempts at contributing towards understanding the concept of child poverty. It suggests that children can be poor while they are still in the womb because they are denied the opportunity to survive when their mothers die before they are born. Children who are deprived from malaria preventive efforts such as the use of insecticide treated nets are poor (UNICEF, 2011). Children, who go hungry and also do not attend school, have no access to potable water, primary health care and the prevalence of diseases that are preventable among children, lack sanitation facilities and experience negative impacts of urbanization, monetization and globalization are suffering child poverty (Abebe, 2014). Negative impacts of urbanization, monetization and globalization can be experienced by both children and adults. However, the impacts and the experience of these factors of change can be different for children and adults. Conceptions of child poverty based on child survival have more popularity especially among development agents such as UNICEF but this is likely to overlook other aspects of children's well-being (Jones and Sumner, 2011).

Clearly, the above meanings and indicators of child poverty are conceptions from the institutional perspective. Meanings of child poverty at the community level from both children and adults' standpoints are unclear. In the next section, I present some meanings of child poverty at the community level split into children's and adults' understandings drawn from both primary and secondary materials.

\section{Some meanings and indicators of child poverty at the community level}

\subsection{Meanings of child poverty from Children's standpoint}

Various meanings of child poverty based on children's understandings have emerged from both developed and developing countries where children were positioned as active agents in the knowledge generation process. From the viewpoint of Ethiopian children, children who live in poverty are those who struggle to eat once a day, feel hungry and tired most of the time, put on worn out clothes and old shoes and also lack school material such as exercise books, pens, pencils, and school bag (Young Lives, 2012). Using food intake, housing conditions and 
children combining schooling and work as indicators of child poverty, Young Lives (2012) established that most children in Ethiopia live in poverty. Just a few children ate between mid-day and evening meals and the food children ate was mostly of lower quality and in small quantities. The Young Lives' findings on what poverty mean to children in Ethiopia is similar to an earlier meaning of child poverty from children's understanding and experience presented by Camfield (2010). The children's understanding of child poverty according to Camfield mirrors how they experienced poverty. Similarly, Witter and Bukokhe (2004) reveal Ugandan children associate child poverty with children's lack of a wide range of things of both material and non-material character. The following are dimensions and indicators of child poverty from the standpoint of children in Uganda.

i. Personal, emotional, and spiritual:

- always wandering around with nothing to do

- submissive to those with more

- lack of dignity because of having to give sex for money

- always worried and never happy, maybe crying all the time

- has mental problems

- low self-esteem

- plays in soil and sand because of nowhere else to play

- has no time to spend with friends

- feeling overwhelmed by problems, feeling miserable and even 'regretting why one was born at all'

- having no peace of mind

- feeling inferior

- does not pray or go to church

ii. Environmental:

- living in an area susceptible to landslides, floods, and drought

- lack of clean and safe water

- lack of latrine

iii. Political:

- living in a war-affected area, including being displaced and abducted

iv. Physical and intellectual:

- always sickly

- child with disabilities who cannot look after her/himself

- has a big head compared to the rest of their body unable to think clearly

- has AIDS

- swollen stomach

v. Financial and Material

- stealing from other people to survive

- eating from the dustbin

- sleeping anywhere, including under people's cars, in people's latrines

- living by begging

- wearing torn and dirty clothing

- doing hard child labor

- $\quad$ seeking domestic work

Extract from Witter and Bukokhe (2004, 648 \& 649),

Beside personal, emotional and material dimensions which are common in the conceptualization of child poverty 
in the literature, children in Uganda are able to connect political instability, negative environmental situations and conditions which emanate from natural occurrences, human activities, physical and intellectual state of children towards explaining and understanding of the meaning of child poverty.

In a qualitative study of children's explanations of poverty and vulnerability in a rural community in northern Ghana, children's accounts of poverty as they experience it indicate their association of child poverty with a lack of voice and uneven distribution of family resources between children and adults (Alenoma, 2014). Also, their definitions of child poverty were around lack of materials for school (books, uniforms, footwear, etc.) and cloths, orphanhood, hunger/denial of food, maltreatment, neglect, children out of school, prevention from playing with peers and children noninvolvement in household decisions on household resource use (Alenoma, 2014). Lack of familial relations for one to run to in times of need was also mentioned as an indicator of poverty in general; suggesting that children who have no closed relations they can run to in times of difficulty are equally poor.

The above meanings of child poverty from children's point of view in developing country context converge and also diverge with some meanings of child poverty from a developed country. From children's accounts in the United Kingdom, child poverty means when children experience material deprivation, social deprivation, and school deprivation, visible signs of poverty and difference, family pressures, additional responsibilities, poor quality housing, homelessness, poor neighborhood and lack social opportunities as a result of living in rural areas (Ridge, 2009). Meanings of child poverty from both the standpoint of children in developing country context and in a developed country context suggest that it is complex and broad or broader compared to the concept of poverty in general or poverty associated with adults.

\subsection{Adults' explanations of child poverty (Rural Northern Ghanaian context)}

Since institutional meanings of child poverty presented earlier largely emanate from data generated from adults, in this sub-paragraph of meanings of child poverty from adults' standpoint at the community level I draw from primary materials generated from four rural communities in northern Ghana in 2015 as part of the empirical materials for my $\mathrm{PhD}$ dissertation. Empirical materials from adults in Kparigu and Boamaasa in the West Mamprusi district of the Northern Region and Dazuuri and Toto in the Lawra district of the Upper West Region revealed some definitions and indicators which are similar but also different from conceptual definitions as well as children's explanations of child poverty. From their definitions, children suffering from child poverty are those who lack some material things or face some challenges: clothes, foot wear, insufficient food intake, illhealth, orphaned, with abject poor parents, without animals, unable to pay dues of community based groups and being lazy or do not engage in any productive activity. A few excerpts on the meaning of child poverty which exemplifies those of other adults in the communities are presented.

A poor child is a child that is orphaned. Interviewee: [Have you seen this mother hen and its chicks? Interviewer: yes!] Chicks can hunt for food but these are too young to fend for themselves. If this mother hen dies and leaves these chicks, they will suffer; they may not grow because they cannot take care of themselves. If we say a child is poor... we know what poverty is... poverty is not because one has no money or not having fowls, goats or cattle. It is when one has no parents or other people around willing to support. A poor child, that is, one without mother or father but if such a child has some God fearing people who can provide the things that children also need and put such a child in school and take care of him/her through school, then such a child will not be poor. If there is a God fearing person who is willing to give such a child some domestic animals to rear and own it, such a child will not be poor because from these animals he can meet his needs (Man, 46 years, and farmer, married with 6 children in Toto community).

A poor child is a child who is lazy. A child who does not have father or mother but is ready to work hard to help himself/herself and is enduring can meet his basic needs and overcome poverty.... a sick child is poor. [Responding furiously]... A child that is not willing to do work to help his parents to make money so that the parents can in turn help him or her is the child that is poor. The child could have more energy than the parents and instead of working hard to help the parent raise money to help him/her through school or take care of him/her when he/she is sick, he loafs around and does not listen to the counsel of his/her parents...this is the child that is poor (Widow in her early 50s with 5 children in Toto community, Lawra district).

In the first excerpt, "children with abject poor parents" and "children who are orphaned" are indicators of child poverty. These explanations of child poverty point to a close link between child poverty and children's position as dependents. When those they depend on live in abject poverty or decease children lose all the care and support 
they enjoy or enjoyed from such people - they become poor. In the conceptual definitions of child poverty, differences between the needs of children and that of adults are often stressed to show the importance of distinguishing child poverty from poverty in general or poverty associated with adults. Both children and adults need the support of others to enhance their well-being, but more so for children because of their dependent status. However, the first excerpt points to children's well-being being tied to the presence of willing and able adults. The second excerpt associate child poverty with children unwillingness to engage in productive or economic activity. Viewed this way, children well-being is tied to what children do for themselves rather than what adults and institutions do for children. Adults' explanations of child poverty as well as conceptual definitions of child poverty show the concept of child poverty is closely linked to the absence of a parent or parents as primary care givers and providers for children. Although the first except does not downplay the importance of material indicators in defining child poverty, poverty of social relations (Alenoma, 2012a) is stressed in the definition or explanation of child poverty while the second is stressing the action or inaction of children themselves being a determinant of the poverty status of children.

\section{Discussion}

Some meanings of child poverty presented above suggest there are varied definitions or understandings of child poverty. The meanings of child poverty suggest that while children in developing country context are concerned with issues regarding survival in their explanations of child poverty, quality of life dominate the definitions of child or children poverty in the case of children in a developed country context. For children in the West, not having adequate money to buy the right clothes, have the right friends and things for Christmas and birthday parties and lack of childhood possessions like toys and games are indicators of child poverty (Ridge, 2009; Muninjin et al, 2006). Although child poverty is generally believed to be different from poverty associated with adults due to differentials in the needs of children and adults, the meaning of child poverty in every societal context is linked to meanings of well-being in the generality of the society which children are a part. The meaning (s) of child poverty which children in both developed and developing country context have provided could be a reflection of the social expectations regarding normal or abnormal way of life for children.

The highlight of meanings of child poverty re/presented show that among children in developing countries especially in Africa there are differences in the meaning of child poverty. Nonetheless, there are similarities. The meaning of child poverty among Ethiopian children takes largely a material dimension while among Ugandan children the meaning of child poverty is more extended with environmental and political dimensions. This shows that the meaning (s) which children give to social phenomena depend on the context which they find themselves. Due to differences in the political history and natural environmental occurrences which Ethiopian and Ugandan children have experienced these factors influence differently their definitions of child poverty. The context specificity of meanings of child poverty from children perspective is clearer juxtaposing the meanings provided by Young Lives (2012), Camfield (2010) and Witter and Bukokhe (2004) on one hand to children's explanations of child poverty in a developed country context presented by Ridge (2009).

Meanings of child poverty from children's standpoint appear to be context specific, how children experience poverty and what they consider important for improving the quality of their lives because children's understandings and definitions of child poverty as highlighted from a developing country context are different from that of children living in developed country context.

The institutional meanings of child poverty presented are dominated by material indicators while community meanings are dominated by relational and emotional indicators. At the community level for children in less developed countries and developed societies alike the quality of their dwelling or sleeping place is important indicator of child poverty, family and social expectations of children, space and voice which children have in the household and the nature of work children engage in are determinants of child poverty. For adults in rural communities in less developed country context, what children do for themselves in any situation they find themselves is an important determinant of child poverty. A poor child is the one who is not willing to work or engage in any economic activity. A poor child is the one without relations willing to support. Poverty of social relations will result in material and emotional poverty of children because they have no one to look up to for their material needs. But the state of the material well-being of the relation(s) children look up is important for understanding the real poverty status of children labelled as poor. 


\section{Policy implications for reducing child poverty}

Based on the meanings of child poverty re/presented, policies for reducing child poverty need to take into account the context specificity nature of the concept of child poverty and recognize that what is meant by a child being poor vary between the institutional and community levels and at the community level children and adults have different conceptions of child poverty. At the community/household level, adults occupy a central position and have a key role to play to taking children out of poverty because of children's dependent status. Thus, any policy aimed at reducing child poverty need to take into account adults' conceptions of child poverty at the community level. Two alternative policy options could work to reduce child poverty in the world. One could be context specific policies aimed at reducing indicators of child poverty resulting from understandings of child poverty in different contexts or what people in different locations consider enhance or impede the well-being of children as well as what children consider relevant for their well-being in different places of the world. For instance, a policy which is designed to ensure that all children of school age are in school in a particular location in the world could be the result of conception of children not being in school being an indicator of child poverty. However, if parents exclude education of children in their definition or conception of child poverty, the policy is likely not to be successfully implemented if this is not incorporated into the policy so as to address this challenge. The other alternative could be considering a grand policy which takes into account the varied meanings of child poverty paying attention to its meanings in different locations in the world, its meaning for adults and children, it meaning at the institutional level and community level and determining points of convergence and divergence of meanings for targeting.

\section{References}

Abebe T., (2014). Orphanhood, Poverty and the Care Dilema: Review of Global Policy Trends, Social Work and Society volume 12 No.1 Accessed on 12.03.09: http://www2.ohchr.org/english/law/crc.htm

Alenoma, G., (2012a) Children Streetism in Tamale Metropolis: the Role of the Family. International Journal of Social Science Tomorow. Vol. 1 No. 4.

Alenoma, G., (2014). Children's Perspectives of Poverty and Vulnerability in Lawra District of the Upper West Region of Ghana: Implications for Social Protection. CODESRIA, (forthcoming), with press.

Camfield, L., (2010) 'Stew Without Bread or Bread Without Stew': Children's Understandings of Poverty in Ethiopia. Children \& Society, 24, 271-281.

Gordon, D, et al. (2003). Child Poverty in the Developing World, The Policy Press, Bristol, (2 - 23).

Jones, N., and Summer A., 2(011). Child Poverty, Evidence and Policy, Mainstreaming Children in International Development, Polity Press (chapter 1)

Minujin, A. et al. (2006). The definition of child poverty: a discussion of concepts and measurements. Environment and Urbanization 18, 2, $481-500$

Thomas P., (2005). Ending Child Poverty \& Securing Child Rights: The Role of Social Protection

A Briefing Paper

Ridge, T., (2009). Living with poverty: A review of the literature on children's and families' experiences of poverty. A report of research carried out by the Centre for the Analysis of Social Policy. Research Report No. 594

UNICEF, (2005a). "Defining Child Poverty”, http://www.unicef.org/sowc05/english/povertyissue.html

UNICEF, (2011). The State of the World's Children

UNICEF, (2012). Measuring Child Poverty: New league tables of child poverty in the world's rich countries. UNICEF Innocenti Research Centre. Report Card 10

Witter S., and Bukokhe J., (2004). Children's perceptions of poverty, participation, and local governance in Uganda, Development in Practice. 14, 5, 645 - 659.

Young Lives, (2012). Children's Experiences and Perceptions of Poverty in Ethiopia:

International Study of Childhood poverty, working paper 